\title{
Contemporary Practice Patterns of Flexible Ureteroscopy for Treating Renal Stones: Results of a Worldwide Survey
}

\author{
Casey A. Dauw, MD,' Laika Simeon, BA, Abdulrahman F. Alruwaily, MBChB, \\ Francesco Sanguedolce, MD, ${ }^{2}$ John M. Hollingsworth, MD, MS, William W. Roberts, MD, \\ Gary J. Faerber, MD, J. Stuart Wolf, Jr., MD, and Khurshid R. Ghani, MBChB, MS ${ }^{1}$
}

\begin{abstract}
Introduction: Flexible ureteroscopy (fURS) is increasingly used in the treatment of renal stones. However, wide variations exist in technique, use, and indications. To better inform our knowledge about the contemporary state of fURS for treating renal stones, we conducted a survey of endourologists worldwide.

Methods: An anonymous online questionnaire assessing fURS treatment of renal stones, consisting of 36 items, was sent to members of the Endourology Society in October 2014. Responses were collected through the SurveyMonkey system over a 3-month period.

Results: Questionnaires were answered by 414 surgeons from 44 countries (response rate 20.7\%). U.S. surgeons accounted for $34.4 \%$ of all respondents. fURS was routinely performed in $80.0 \%$ of institutions, with $40.0 \%$ of surgeons performing $>100$ cases/year. Respondents considered fURS to be first-line therapy for patients with renal stones $<2 \mathrm{~cm}$ and lower pole calculi. A substantial minority $(11.3 \%)$ preferred fURS as a primary treatment modality for renal stones $>2 \mathrm{~cm}$. Basket displacement for lower pole stones was routinely performed by $55.8 \%$. Ureteral access sheaths (UAS) were preferred for every case by 58.3\%. Respondents frequently utilized high-power lasers and dusting techniques. Criteria for determining stone-free rate were defined as zero fragments or residual fragment $(\mathrm{RF})<1,<2,<3$, and $<4 \mathrm{~mm}$ by $30.9 \%, 8.9 \%, 31.5 \%, 15.8 \%$, and $11.2 \%$ of respondents, respectively.

Conclusion: The overwhelming majority of endourologists surveyed consider fURS as a first-line treatment modality for renal stones, especially those $<2 \mathrm{~cm}$. Use of UAS, high-power holmium lasers, and dusting technique has become popular among practitioners. When defining stone free after fURS, the majority of endourologists used a zero fragment or $\mathrm{RF}<2 \mathrm{~mm}$ definition.
\end{abstract}

\section{Introduction}

$\mathbf{T}$ REATMENT OPTIONS FOR PATIENTS with renal stones mainly comprise one of three procedures: percutaneous nephrolithotomy (PCNL), shockwave lithotripsy (SWL), and flexible ureteroscopy (fURS). The ability to use the holmium laser to perform intracorporeal lithotripsy, as well as advances in endoscope technology and ancillary instrumentation, has seen fURS emerge as an increasingly popular method for managing patients with upper urinary-tract stones. In the United States, newly qualified urologists are increasingly using URS for the majority of stone removal procedures. ${ }^{1}$

Despite recent population-level evidence demonstrating increasing utilization of fURS, ${ }^{2-4}$ little information exists on contemporary practice patterns of fURS for the treatment of renal calculi. ${ }^{5}$ While guidelines recommend fURS for treating renal stones $<1.5 \mathrm{~cm}$, ${ }^{6}$ considerable differences exists among urologists in the technique, use, and indications of fURS. In particular, the variation in the use of disposable equipment, such as ureteral access sheaths (UAS) or nitinol retrieval devices, and the utilization of more powerful high-watt holmium laser systems in the modern era of fURS, have not been thoroughly evaluated. Recently, the European Association of Urology (EAU) conducted a survey on the use of fURS for the treatment of renal calculi in Europe. ${ }^{5}$ To study a broader collection of urologists throughout the world, we modified this questionnaire and surveyed members of the Endourology Society about multiple facets of renal calculi treatment using fURS. Our specific aim was to explore differences in the fURS technique and practice among endourologists.

\footnotetext{
${ }^{1}$ Department of Urology, University of Michigan Health System, Ann Arbor, Michigan.

${ }^{2}$ Department of Urology, North Bristol NHS Trust, Bristol, United Kingdom.
} 


\section{Methods}

In October 2014, an anonymous online questionnaire characterizing fURS use in the management of renal stones was disseminated to all members of the Endourology Society through e-mail. The survey instrument contained 36 discrete questions divided into six domains to capture demographic information, level of surgeon experience, indications, surgical technique, postoperative stent management and tracking, and postsurgical follow-up. Questions were multiple choice with the option for free text responses. See Appendix for details on questions asked. Respondents were further subdivided based on region of residence for descriptive purposes such that those from North America, Europe, and other regions could be compared with respect to various responses.

The survey was conducted using the web-based SurveyMonkey system (Palo Alto, CA). Respondents were invited to participate through an introductory email from the Endourology Society membership office with a brief description of the survey and a hyperlink of the survey. A second reminder e-mail was sent a month later and the survey remained open for 3 months. The survey was deemed exempt from requiring review by the Institutional Review Board at the University of Michigan. To improve participation, a \$200 award was offered to one respondent selected at random. The study was funded by the Endourology Division of the Department of Urology, University of Michigan.

\section{Results}

The survey was disseminated to $\sim 2000$ members of the Endourology Society; $414(20.7 \%)$ responded. Those responding represented 44 countries with the largest percentage of respondents practicing in the United States $(34.4 \%)$, United Kingdom (9.8\%), and Canada (5.3\%) (Table 1). More than $60 \%$ of respondents were between the ages of 40 and 59; $2 \%$ were $<30$ years, $23 \%$ were between 30 and 39 and $14 \%$ were older than 60 years. Approximately $60 \%$ of respondents had completed an endourology fellowship, while $80.5 \%$ indicated they were a subspecialist with an interest in urinary stone disease.

The case volume of fURS performed annually is depicted in Figure 1; nearly $40 \%$ of respondents performed fURS more than 100 times per year. fURS was performed routinely in the institution of $80 \%$ of respondents.

\section{Indications and planning}

With regard to indications and surgical planning, respondents overwhelmingly (96.4\%) felt that fURS could be used as a first-line modality to treat renal stones. To this effect, there was a wide range of clinical situations in which respondents felt that fURS was an appropriate primary treatment, the most popular being stone in horsehoe kidney $(72.1 \%)$ and stone in the lower pole (71\%) (Fig. 2). Patients were considered for staged fURS (more than one URS planned in advance) when the renal stone size $(\mathrm{cm})$ was $1-1.5$ (9.7\%), >1.5 (20.2\%), >2.0 (27.0\%), and >2.5 (16.3\%).

\section{Surgical technique}

When examining techniques, there was variability in the way urologists approached the ureteral orifice before advancing the ureteroscope. Whereas some placed working and/or
Table 1. Distribution of Urologists Responding to Survey on FleXible Ureteroscopy

\begin{tabular}{|c|c|c|}
\hline Country & Respondents (N) & Percent \\
\hline Argentina & 3 & 0.8 \\
\hline Australia & 4 & 1.1 \\
\hline Bangladesh & 1 & 0.3 \\
\hline Belgium & 3 & 0.8 \\
\hline Brazil & 11 & 3.1 \\
\hline Bulgaria & 2 & 0.6 \\
\hline Canada & 19 & 5.3 \\
\hline Chile & 3 & 0.8 \\
\hline China & 10 & 2.8 \\
\hline Colombia & 8 & 2.2 \\
\hline Egypt & 3 & 0.8 \\
\hline El Salvador & 1 & 0.3 \\
\hline France & 6 & 1.7 \\
\hline Germany & 13 & 3.6 \\
\hline Greece & 5 & 1.4 \\
\hline India & 14 & 3.9 \\
\hline Indonesia & 1 & 0.3 \\
\hline Iran & 4 & 1.1 \\
\hline Ireland & 1 & 0.3 \\
\hline Israel & 1 & 0.3 \\
\hline Italy & 9 & 2.5 \\
\hline Japan & 11 & 3.1 \\
\hline Lithuania & 4 & 1.1 \\
\hline Mexico & 8 & 2.2 \\
\hline Netherlands & 6 & 1.7 \\
\hline Nigeria & 1 & 0.3 \\
\hline Norway & 2 & 0.6 \\
\hline Pakistan & 2 & 0.6 \\
\hline Philippines & 3 & 0.8 \\
\hline Portugal & 1 & 0.3 \\
\hline Romania & 1 & 0.3 \\
\hline Russia & 6 & 1.7 \\
\hline Saudi Arabia & 3 & 0.8 \\
\hline Singapore & 4 & 1.1 \\
\hline South Africa & 7 & 1.9 \\
\hline South Korea & 2 & 0.6 \\
\hline Spain & 7 & 1.9 \\
\hline Thailand & 1 & 0.3 \\
\hline Turkey & 8 & 2.2 \\
\hline United Arab Emirates & 1 & 0.3 \\
\hline United Kingdom & 35 & 9.7 \\
\hline United States & 123 & 34.3 \\
\hline Venezuela & 1 & 0.3 \\
\hline
\end{tabular}

safety wires $(38.0 \%)$, others first performed semirigid ureteroscopy $(19.7 \%)$, retrograde pyelogram $(14.6 \%)$, or placed a UAS $(25.7 \%)$. Only $1.9 \%$ of respondents performed fURS without a wire.

In the event that the ureteroscope was unable to be advanced beyond the ureteral orifice, $27.6 \%$ of respondents stated they would dilate the orifice with ureteral dilators, $27.4 \%$ stated they would dilate with a semirigid ureteroscope, $25.5 \%$ stated they would place a ureteral stent and arrange for fURS at a later date, $18.2 \%$ would perform balloon dilation of the ureteral orifice, $1.1 \%$ would switch to another treatment modality, and $0.2 \%$ would perform a ureterotomy.

\section{UAS/basket retrieval}

Indications for use of UAS during fURS are provided in Figure 3, with $58.3 \%$ of respondents stating that they prefer to 


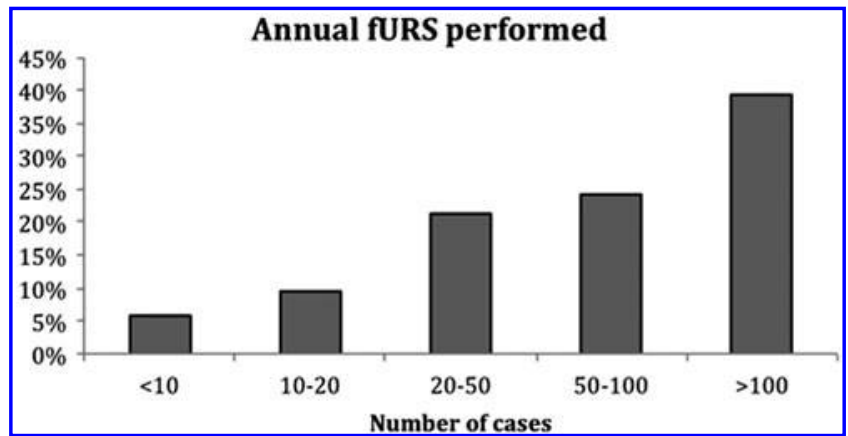

FIG. 1. Number of flexible ureteroscopies (fURS) performed annually.

use a UAS for every case. With regard to the strategy of whether to retrieve stone fragments or not, $26.7 \%$ of respondents actively retrieved all stone fragments, whereas $37.4 \%$ only retrieved large fragments-leaving those that were small enough to pass spontaneously (Fig. 4). When dealing with stones in the lower pole, most $(55.8 \%)$ routinely used the basket displacement technique to move stones to a less dependent calix for fragmentation.

\section{Holmium laser}

Respondents uniformly utilized a holmium laser for stone fragmentation, and the vast majority worked in centers that owned their own laser $(85.6 \%)$. High-power systems $(\geq 100 \mathrm{~W})$ were utilized by $41.1 \%$, while lower power $(20$ $30 \mathrm{~W})$ systems were used by $44.2 \%$. The majority of respondents $(54.8 \%)$ preferred a $200-\mu \mathrm{m}$ laser fiber size as their go to fiber. The dusting technique (i.e., low pulse energy and high frequency $0.2-0.5 \mathrm{~J} \times 30-50 \mathrm{~Hz}$ ) was used by $67 \%$ of the respondents.

\section{Postprocedural aspects}

Respondents indicated that in their practice, following completion of fURS, a ureteral stent was placed in all cases $63.9 \%$ of the time, whereas the remainder stated that a ureteral stent was only placed if warranted by intraoperative factors. Only $42.8 \%$ of respondents indicated that their practice maintained a stent registry to keep track of indwelling stents in patients (Fig. 5). Finally, respondents indicated that an abdominal radiograph, in combination with ultrasonography

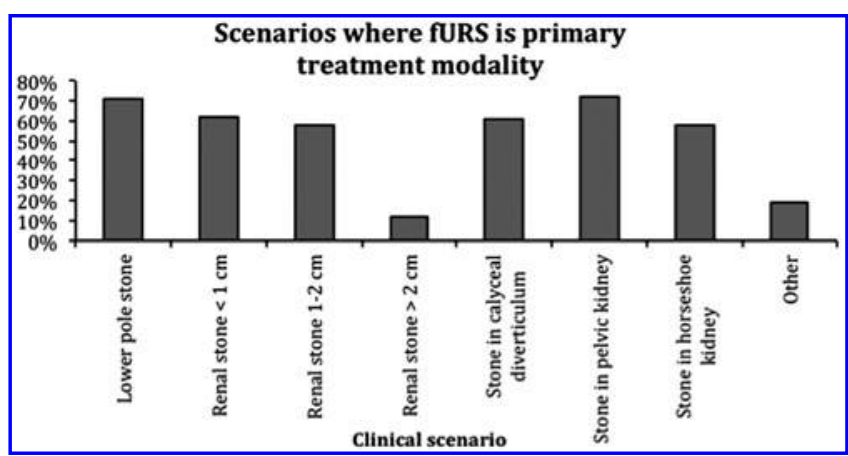

FIG. 2. Clinical scenarios in which fURS is appropriate first-line treatment for renal stones.

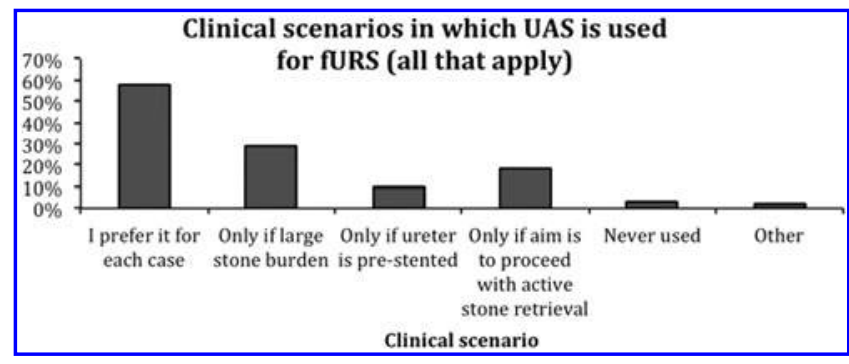

FIG. 3. Indications for ureteral access sheath during fURS.

(40.8\%), abdominal radiograph alone $(32.8 \%)$, computed tomography $(24.7 \%)$, or ultrasound alone $(1.7 \%)$, was used to assess stone burden following fURS. The time point at which imaging was undertaken to assess the stone-free rate (SFR) varied (Fig. 6). Table 2 demonstrates the variation among urologists for determining what fragment size is important for defining the SFR.

\section{Variation in technique by geographic location}

After subdividing respondents by location of residence (North America, Europe, other), differences were noted with regard to selected questions as indicated in Table 3.

\section{Discussion}

The present survey-based study was conducted to better understand the worldwide variation in the fURS technique and clinical practice. In summary, the majority of urologists who responded were fellowship trained and many estimated a volume of more than 100 procedures performed annually. Most respondents felt fURS was applicable to a wide range of clinical scenarios, including varying stone size, stone location, and anatomic variations. Furthermore, respondents routinely used UAS and were familiar with high-watt holmium lasers for fURS, as well as using new techniques such as dusting for stone fragmentation.

One interesting observation highlighted by the survey results was that urologists find fURS to be an acceptable surgical technique for a wide range of indications. Recent EAU guidelines state that fURS is a reasonable option for treatment of renal stones $<2 \mathrm{~cm}$. In the present study, more than $10 \%$ of respondents indicated that fURS was considered an appropriate treatment for stones $>2 \mathrm{~cm}$, a size that traditionally

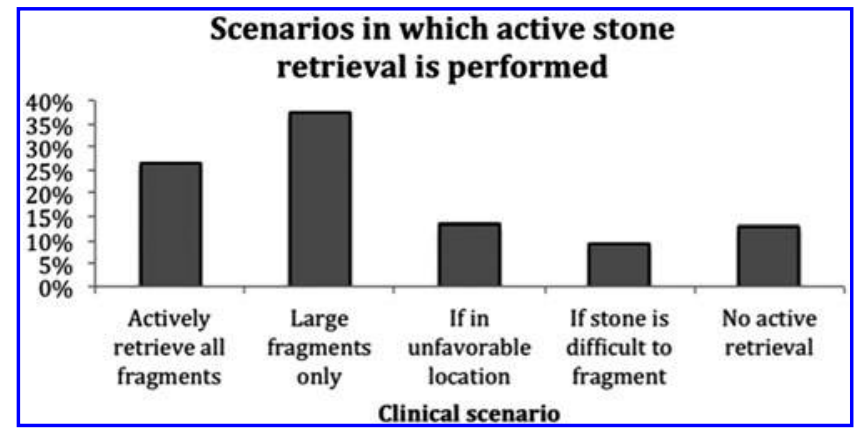

FIG. 4. Responses to the questions "Regarding fragmentation of a stone and whether to retrieve fragments or not, what is your typical strategy?", 


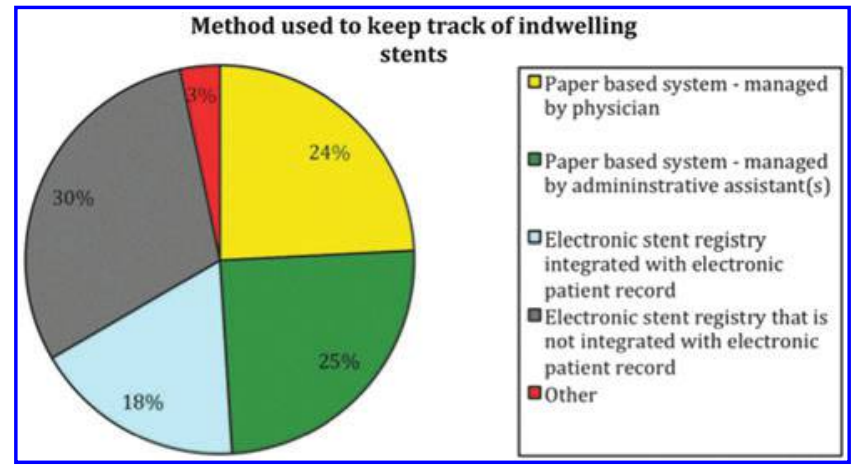

FIG. 5. Strategies for ureteral stent management and tracking.

would be managed through PCNL. Moreover, despite a nonstatistical difference in SFRs reported in the prospective randomized controlled study comparing SWL with ureteroscopy for lower pole stones $<1 \mathrm{~cm}, 71 \%$ of respondents felt fURS was the first-line therapy in this situation. ${ }^{7}$

Two recent studies have demonstrated that fURS is a reasonable approach for renal stones $>2 \mathrm{~cm}$. In a metaanalyses of urinary stones $>2 \mathrm{~cm}$ managed by fURS, Aboumarzouk et al. found that for a mean stone size of $2.5 \mathrm{~cm}$, SFRs were $93.7 \%$ with a major complication rate of $5.3 \% .^{8} \mathrm{~A}$ similar study by Breda and Angerri for stones $>2.5 \mathrm{~cm}$ showed an overall SFR of $89.3 \%$ with a major complication rate of $8 \% .^{9}$ The average number of treatments required per patient was 1.6 in each study. These studies highlight that the combination of technologic advances and endourologic expertise may be broadening the application of fURS, a clinical impression reflected by our survey.

Another observation made from our study was the frequency with which surgeons utilized the UAS. More than half of respondents indicated in the survey that they used a UAS for every case, whereas an additional $25 \%$ used it in selected clinical scenarios. Advantages of the UAS include improving longevity of the flexible ureteroscope ${ }^{10}$ as well as decreasing intrarenal pressure during fURS. ${ }^{11}$ The UAS is often used to ease stone retrieval, as noted by $31.0 \%$ of respondents. Despite these benefits, outcomes such as SFR, arguably one of the most important indicators of effective fURS, have shown mixed results. L'esperance et al. evaluated 256 patients undergoing fURS for renal calculi stratifying outcomes based on whether a UAS was used or not. The SFR in the UAS group was $79 \%$, significantly higher than the non-UAS group

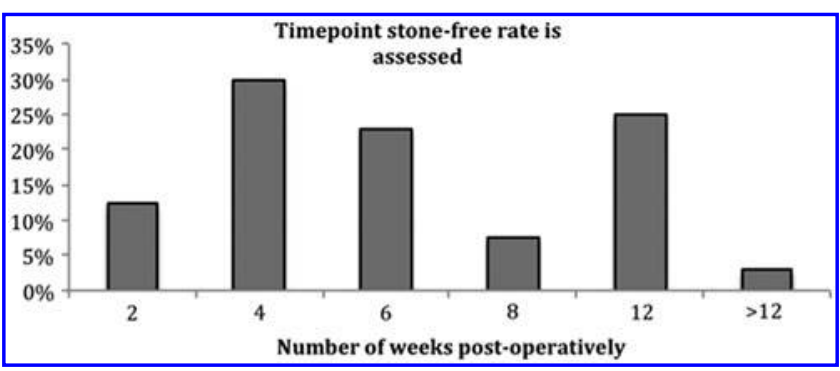

FIG. 6. Time point after fURS when stone-free status is determined.
Table 2. Residual Fragment Size Considered to Be Stone Free

\begin{tabular}{lcc}
\hline Fragment size $(\mathrm{mm})$ & Respondent $(\mathrm{N})$ & Percent \\
\hline Zero fragments & 108 & 30.9 \\
$<1$ & 31 & 8.9 \\
$<2$ & 110 & 31.5 \\
$<3$ & 55 & 15.8 \\
$<4$ & 39 & 11.2 \\
$<5$ & 6 & 1.7 \\
\hline
\end{tabular}

$(67 \%) .{ }^{12}$ However, a more recent study did not find use of a UAS to be associated with improved SFRs with stone size being the only variable predictive of SFR on regression analysis. ${ }^{13}$ The paucity of evidence is reflected in the variation of use by respondents in our survey.

Our study provided some interesting findings with respect to practice patterns surrounding active stone retrieval vs fragmentation. Specifically, many respondents actively retrieved stone fragments and only a few indicated that they seek to fragment the stone into pieces they feel will pass spontaneously, without any need for extraction. Certainly, debate regarding the optimal fragmentation and retrieval technique has been ongoing. ${ }^{14}$ Currently, no Level 1 evidence is available that answers the following question: "should you perform active retrieval or is fragmentation only enough after fURS for renal stones?'” More recently, newer laser lithotripsy techniques such as dusting utilizing highwatt holmium systems have been popularized. ${ }^{15}$ Dusting uses a high-frequency, low-pulse energy setting, such as 30$50 \mathrm{~Hz} \times 0.2-0.5 \mathrm{~J}$, which seeks to fragment stones to fine powder and small fragments, and thus reduce the need to retrieve fragments. We were surprised to find out that twothirds of respondents indicated using this technique. So far, there are limited clinical data as to whether this method has significant advantages over existing techniques, and further studies are needed to confirm its utility.

Interestingly, more than $63 \%$ of respondents indicated that a ureteral stent was left in place following fURS. There have been numerous clinical trials conducted to investigate the utility of routine ureteral stenting following ureteroscopy. A recent systematic review and meta-analysis by Nabi et al. found that patients in whom a ureteral stent was placed reported higher rates of dysuria, urgency, and frequency without a statistically significant increased SFR, although this was limited by study heterogeneity. ${ }^{16}$ Given the uncertainty on this issue and lack of improvement in SFR reported in the meta-analysis, it is notable that so many respondents routinely stent their patients following fURS.

Our study has also provided some important information on determining the preferred method and criteria for determining the SFR after fURS. Approximately $75 \%$ used an abdominal radiograph, renal ultrasound, or a combination of the two as the imaging modality of choice for assessing residual stone burden. Most respondents use to perform this within 6 weeks following surgery. Certainly, use of ultrasound following URS is encouraged to rule out silent hydronephrosis, which can occur in up to $2 \%-5 \%$ of patients. ${ }^{17-19}$ Less agreed upon, however, is the definition of SFR following fURS. The term clinically insignificant residual fragment $(\mathrm{RF})$ was introduced 
Table 3. Variation in Region of Practice and Techniques

\begin{tabular}{|c|c|c|c|}
\hline & USA/Canada & Europe & Other \\
\hline $\begin{array}{l}\text { Do you consider UAS use during fURS?(Q15) } \\
\text { UAS used for every case (\%) }\end{array}$ & 46.9 & 53.7 & 75.2 \\
\hline $\begin{array}{l}\text { What is your main reason for UAS use? (Q17) } \\
\text { UAS used for stone retrieval (\%) }\end{array}$ & 47.2 & 21.5 & 20.2 \\
\hline $\begin{array}{l}\text { What is your strategy to remove stone fragments } \\
\text { Only remove large fragments (\%) } \\
\text { All fragments removed regardless of size (\%) }\end{array}$ & $\begin{array}{l}36.0 \\
34.4\end{array}$ & $\begin{array}{l}28.4 \\
27.4\end{array}$ & $\begin{array}{l}46.6 \\
22.0\end{array}$ \\
\hline $\begin{array}{l}\text { What is your laser power? (Q22) } \\
100 \mathrm{~W}(\%)\end{array}$ & 45.2 & 26.1 & 37.4 \\
\hline $\begin{array}{l}\text { Do you perform dusting (high frequency/low pul } \\
\text { Yes }(\%)\end{array}$ & Q26) 65.9 & 73.1 & 64.0 \\
\hline $\begin{array}{l}\text { What imaging do you use to assess stone-free st } \\
\text { KUB XR if stone is radiopaque (\%) } \\
\text { KUB XR and US if stone is radiopaque (\%) }\end{array}$ & $\begin{array}{l}35.5 \\
24.2\end{array}$ & $\begin{array}{l}34.4 \\
30.1\end{array}$ & $\begin{array}{l}25.7 \\
23.9\end{array}$ \\
\hline $\begin{array}{l}\text { At what point do you assess stone-free status pos } \\
6 \text { weeks }(\%) \\
1 \text { month }(\%)\end{array}$ & $\begin{array}{l}32.5 \\
30.9\end{array}$ & $\begin{array}{l}12.0 \\
27.2\end{array}$ & $\begin{array}{l}22.9 \\
28.1\end{array}$ \\
\hline $\begin{array}{l}\text { How do you define stone-free status? (Q36) } \\
\text { No fragments }(\%) \\
<2 \text { mm fragments }(\%)\end{array}$ & $\begin{array}{l}41.1 \\
33.9\end{array}$ & $\begin{array}{l}32.7 \\
28.3\end{array}$ & $\begin{array}{l}21.9 \\
31.6\end{array}$ \\
\hline
\end{tabular}

For some questions, the two most common responses are provided for comparative assessment.

fURS = flexible ureteroscopy; KUB = kidney, ureter, and bladder radiograph; UAS = ureteral access sheaths; XR =X-ray; US = ultrasound.

for asymptomatic noninfectious RFs $<4-5 \mathrm{~mm}$ following SWL, and many studies adopted this metric when reporting the success of stone treatment. ${ }^{20}$ However, recent computed tomography-based studies have shown that instead of RF $\leq 4 \mathrm{~mm}$, sizes $\leq 2$ or $\leq 3 \mathrm{~mm}$ might be more appropriate for determining the clinical significance of stone free and risk of retreatment after stone surgery. ${ }^{21,22}$ The lack of consensus in our field about imaging utilization and criteria ${ }^{23}$ is demonstrated in our study where nearly $30 \%$ felt stone free was defined as zero fragments on imaging, whereas the remainder felt $\mathrm{RF}<1-4 \mathrm{~mm}$ was appropriate.

Two prior surveys have investigated practice patterns surrounding upper tract urinary stone treatment use among urologists. $^{24,25}$ Bandi et al. surveyed members of the North Central Section of the American Urological Association in 2006 and found that fURS was largely reserved for proximal and distal ureteral calculi. Subcentimeter renal stones were largely managed with SWL, whereas larger stones were managed with PCNL. This is in contrast to our study, where upward of $90 \%$ of urologists indicated fURS an appropriate first-line therapy for renal calculi of varying sizes and location. Our results are similar to a recent EAU survey conducted by Sanguedolce et al. wherein $95 \%$ of surveyed urologists preferred fURS as first-line therapy for renal calculi for a variety of clinical scenarios, and where also use of UAS was prevalent. ${ }^{5}$ Unlike our study, the EAU survey did not assess the use of holmium laser systems or practice patterns on postprocedure imaging and criteria for SFR.

The results of our study are useful in that they depict the demographics and practice patterns of an experienced group of specialty-trained urologists. However, certain limitations must be acknowledged. First, this study represents a highly specialized cohort of urologists, and thus, the findings may not be generalizable to general urologists without specialty training in endourology. In addition, our survey response rate of $21 \%$ is suboptimal and may influence the generalizability of our results. Furthermore, due to a general lack of rigorous level-one evidence regarding the benefit of several techniques described in the article (UAS use and dusting), observations from respondents serve more as descriptive findings rather than evidence of appropriate use. Moreover, the cost implications of technologic innovation with lack of proven benefit outside of observational studies must be considered carefully when treating patients with renal stones. Finally, there is always the possibility that due to reporting bias, opinions reflected in this survey do not necessarily mirror clinical practice. Nevertheless, our study response rate is similar to prior endourology surveys, ${ }^{24}$ and even higher than more recent ones to Endourology Society members. ${ }^{25}$ Finally, it is possible that some urologists may not be fully aware how best to utilize the holmium laser power settings, and further survey-based studies are needed to verify our findings.

\section{Conclusion}

The use of fURS for treating renal calculi has expanded such that it is considered first-line therapy by endourologists for varying stone sizes, stone locations, and anatomical variations. UAS, high-power holmium lasers, and dusting technique are now utilized on a regular basis. When defining stone-free status after fURS, the majority of urologists surveyed used a zero fragment or RF $<2 \mathrm{~mm}$ definition. Although there is consensus regarding certain aspects of fURS technique and practice, several controversies still exist that merit further investigation. 


\section{Acknowledgments}

We thank Greg Mowatt from the Department of Urology for helping with the IRB application, as well as Michele Paoli from the Endourology Society for assistance with disseminating the survey to its members.

\section{Author Disclosure Statement}

Khurshid Ghani is a consultant for Lumenis, Inc., and Boston Scientific.

\section{References}

1. Matlaga BR, American Board of Urology. Contemporary surgical management of upper urinary tract calculi. $\underline{\mathrm{J} \text { Urol }}$ 2009;181:2152-2156.

2. Ordon M, Urbach D, Mamdani M, et al. The surgical management of kidney stone disease: A population based time series analysis. J Urol 2014;192:1450-1456.

3. Lee M-C, Bariol SV. Evolution of stone management in Australia. BJU Int 2011;108 Suppl 2:29-33.

4. Ghani KR, Sammon JD, Karakiewicz PI, et al. Trends in surgery for upper urinary tract calculi in the USA using the Nationwide Inpatient Sample: 1999-2009. BJU Int 2013;112:224-230.

5. Sanguedolce F, Liatsikos E, Verze $P$, et al. Use of flexible ureteroscopy in the clinical practice for the treatment of renal stones: Results from a large European survey conducted by the EAU Young Academic Urologists-Working Party on Endourology and Urolithiasis. Urolithiasis 2014;42: 329-334.

6. Turk C, Knoll T, Petrik A. Guidelines on Urolithiasis, EAU Guidelines - Urolithiasis 2014. www.uroweb.org Available at: http://uroweb.org/gls/pdf/22\%20Urolithiasis_LR.pdf (accessed February 26, 2015).

7. Pearle MS, Lingeman JE, Leveillee R, et al. Prospective randomized trial comparing shock wave lithotripsy and ureteroscopy for lower pole caliceal calculi $1 \mathrm{~cm}$ or less. J Urol 2008;179:S69-S73.

8. Aboumarzouk OM, Monga M, Kata SG, et al. Flexible ureteroscopy and laser lithotripsy for stones $>2 \mathrm{~cm}$ : A systematic review and meta-analysis. J Endourol 2012;26:12571263.

9. Breda A, Angerri O. Retrograde intrarenal surgery for kidney stones larger than $2.5 \mathrm{~cm}$. Curr Opin Urol 2014;24: 179-183.

10. Pietrow PK, Auge BK, Delvecchio FC, et al. Techniques to maximize flexible ureteroscope longevity. Urology 2002;60: 784-788.

11. Auge BK, Pietrow PK, Lallas CD, et al. Ureteral access sheath provides protection against elevated renal pressures during routine flexible ureteroscopic stone manipulation. $\mathbf{J}$ Endourol 2004;18:33-36.

12. L'esperance JO, Ekeruo WO, Scales CD, et al. Effect of ureteral access sheath on stone-free rates in patients undergoing ureteroscopic management of renal calculi. Urology 2005;66:252-255.

13. Berquet G, Prunel P, Verhoest G, et al. The use of a ureteral access sheath does not improve stone-free rate after ureteroscopy for upper urinary tract stones. World J Urol 2014;32:229-232.

14. Ghani KR. Dusting vs. Fragmentation and other highlights from WCE 2013. www.bjuinternational.com Available at: http://bjuinternational.com/bjui-blog/world-congressof-endourology/ (accessed February 26, 2015).

15. Kronenberg P, Traxer O. Update on lasers in urology 2014: Current assessment on holmium:yttrium-aluminum-garnet (Ho:YAG) laser lithotripter settings and laser fibers. World J Urol 2015;33:463-469.

16. Nabi G, Cook J, N'Dow J, et al. Outcomes of stenting after uncomplicated ureteroscopy: Systematic review and metaanalysis. BMJ 2007;334:572-575.

17. Manger JP, Mendoza PJ, Babayan RK, et al. Use of renal ultrasound to detect hydronephrosis after ureteroscopy. I Endourol 2009;23:1399-1402.

18. Weizer AZ, Auge BK, Silverstein AD, et al. Routine postoperative imaging is important after ureteroscopic stone manipulation. J Urol 2002;168:46-50.

19. Fulgham PF, Assimos DG, Pearle MS, et al. Clinical effectiveness protocols for imaging in the management of ureteral calculous disease: AUA technology assessment. J Urol 2013;189:1203-1213.

20. Streem SB, Yost A, Mascha E. Clinical implications of clinically insignificant store fragments after extracorporeal shock wave lithotripsy. J Urol 1996;155:1186-1190.

21. Rebuck DA, Macejko A, Bhalani V, et al. The natural history of renal stone fragments following ureteroscopy. Urology 2011;77:564-568.

22. Raman JD, Bagrodia A, Gupta A, et al. Natural history of residual fragments following percutaneous nephrostolithotomy. Expulsive therapy versus early endoscopic stone removal in patients with acute renal colic: A comparison of indirect costs. 2009;181:1163-1168.

23. Hyams ES, Monga M, Pearle MS, et al. A prospective, multiinstitutional study of flexible ureteroscopy for proximal ureteral stones smaller than $2 \mathrm{~cm}$. J Urol 2015;193:165-169.

24. Bandi G, Best SL, Nakada SY. Current practice patterns in the management of upper urinary tract calculi in the north central United States. J Endourol 2008;22:631-636.

25. Sivalingam S, Cannon ST, Nakada SY. Current practices in percutaneous nephrolithotomy among endourologists. J Endourol 2014;28:524-527.

Address correspondence to: Khurshid R. Ghani, MBChB, MS Department of Urology University of Michigan Health System 2800 Plymouth Road NCRC Building 16, 114W Ann Arbor, MI 48109

E-mail: kghani@med.umich.edu

$\begin{aligned} & \text { Abbreviations Used } \\ \text { EAU } & =\text { European Association of Urology } \\ \text { fURS } & =\text { flexible ureteroscopy } \\ \text { KUB } & =\text { kidney, ureter, and bladder radiograph } \\ \text { PCNL } & =\text { percutaneous nephrolithotomy } \\ \mathrm{RF} & =\text { residual fragment } \\ \mathrm{SFR} & =\text { stone-free rate } \\ \mathrm{SWL} & =\text { shockwave lithotripsy } \\ \mathrm{UAS} & =\text { ureteral access sheath }\end{aligned}$




\section{Appendix-Survey Instrument}

Question 1: What practice is your practice located in?

Question 2: How old are you?

Question 3: Do you have fellowship training in endourology/stones?

Question 4: Which of the following would you consider yourself?

- General urologist

- Urologist with specialty interest in stone disease

- Urologist with specialty interest in another area

Question 5: Approximately how often is flexible ureteroscopy used to treat renal stones at your center?

- Never

- Infrequently

- Sometimes

- Routinely

Question 6: Approximately how many flexible ureteroscopies to treat renal stones do you perform per year?

- 0

- $<10$

- $10-20$

- 20-50

- 50-100

- $>100$

Question 7: If you do not perform flexible ureteroscopy for renal stones please select why not.

- Access to equipment

- Prefer different treatment modality

- Urolithiasis is not my specialty

- Other (explain)

Question 8: Do you think flexible ureteroscopy to treat renal stones can be considered a first-line procedure in specific cases?

- Yes

- No

Question 9: In which scenarios would you use flexible ureteroscopy to treat a stone?

- Lower pole stone

- Renal stone $<1 \mathrm{~cm}$

- Renal stone $1-2 \mathrm{~cm}$

- Renal stone $>2 \mathrm{~cm}$

- Stone in caliceal diverticulum

- Stone in pelvic kidney

- Stone in horseshoe kidney

- Other

Question 10: When do you consider a patient for staged flexible ureteroscopy to treat renal calculi?

- Total renal stone burden $1-1.5 \mathrm{~cm}$

- Total renal stone burden $>1.5 \mathrm{~cm}$

- Total renal stone burden $>2 \mathrm{~cm}$

- Total renal stone burden $>2.5 \mathrm{~cm}$

- I don't perform staged procedures

Question 11: What steps do you typically perform before advancing a flexible ureteroscope?

- I place a working wire first

- I place a working and safety wire first

- I perform semirigid ureteroscopy first

- I place a ureteral access sheath first

- I perform a retrograde pyelogram first

- I perform flexible ureteroscopy without any wire 
Question 12: If you are unable to advance a flexible scope beyond the ureteral orifice, which of the following procedures do you perform first?

- I perform passive dilation with ureteral dilator(s)

- I perform active dilation with a balloon dilator

- I perform a ureterotomy

- I place a ureteral stent and arrange for flexible ureteroscopy later

- I perform dilation with semirigid ureteroscopy

- I prefer to switch to another treatment option

Question 13: If you are able to advance flexible scope beyond the ureteral orifice but then unable to advance beyond the lower ureter, which of the following procedures do you perform first?

- I perform passive dilation with ureteral dilator(s)

- I perform active dilation with a balloon dilator

- I perform a ureterotomy

- I place a ureteral stent and arrange for flexible ureteroscopy later

- I perform dilation with semirigid ureteroscopy

- I prefer to switch to another treatment option

Question 14: How do you routinely advance the flexible ureteroscope into the kidney?

- Under fluoroscopic control

- Under direct vision

- Under fluoroscopic control and direct vision

Question 15: How do you consider the use of the ureteral access sheath during flexible ureteroscopy for treating renal stones? (Select all that apply)

- I prefer it for each case

- Only if large stone burden

- Only if ureter is prestented

- Only if aim is to proceed with active stone retrieval

- Never used

- Other

Question 16: Which size of ureteral access sheath (UAS) do you typically use (in nonstented ureter)?

- $9.5-11.5 \mathrm{~F}$

- $10-12 \mathrm{~F}$

- $11-13 \mathrm{~F}$

- $12-14 \mathrm{~F}$

- $13-15 \mathrm{~F}$

- $14-16 \mathrm{~F}$

Question 17: What is your main reason for using a UAS?

- To keep pressure in the collecting system low

- To perform retrieval of stone

- For better vision and irrigation

- It is easier to perform flexible ureteroscopy with this

Question 18: When inserting a UAS, what wire do you use for its placement?

- polytetrafluoroethylene (PTFE) wire

- Hydrophilic wire

- Hybrid wire

- Super-stiff wire

Question 19: When dealing with lower pole renal stones, what strategy do you follow?

- I prefer to displace the stone to a less dependent area with a nitinol basket and start fragmentation in a new area

- I prefer to start the fragmentation of the stone in situ in the lower pole

- Indifferent, I can retrieve the stone or not according to the situation 
Question 20: Regarding fragmentation of a stone and whether to retrieve fragments or not, what is your typical strategy?

- I actively retrieve all fragments with a nitinol basket

- I retrieve only the bigger fragments with a nitinol basket and leave those that I think are small enough to pass spontaneously

- I don't retrieve any fragments. I perform fragmentation of the stone until I think all the fragments are small enough to pass spontaneously

- I retrieve depending on the stone size and location

- I retrieve only in patients with prestented ureters

- I retrieve only when stone is difficult to fragment into small bits or if anatomy is unsuitable for fragment passage

Question 21: Does your center/practice have access to a holmium laser for ureteroscopic lithotripsy?

Question 22: What power is your holmium laser?

- $20 \mathrm{~W}$

- $30 \mathrm{~W}$

- $50 \mathrm{~W}$

- $60-80 \mathrm{~W}$

- $100 \mathrm{~W}$

- $120 \mathrm{~W}$

Question 23: Is your laser $?$

- Owned by center

- Leased but always on-site

- Leased and comes to center from outside as needed

Question 24: What is your standard "go to" laser fiber size when treating a renal stone?

- 150 fiber

- 200 fiber

- 270 fiber

- 365 fiber

- depends on location

Question 25: What is your standard setting on the holmium laser for stone fragmentation?

- $0.5-1.0 \mathrm{~J} \times 5-10 \mathrm{~Hz}$

- $0.5-1.0 \mathrm{~J} \times 10-15 \mathrm{~Hz}$

- $0.5-1.0 \mathrm{~J} \times 15-20 \mathrm{~Hz}$

- $1.0-1.5 \mathrm{~J} \times 5-10 \mathrm{~Hz}$

- $1.0-1.5 \mathrm{~J} \times 10-15 \mathrm{~Hz}$

- $1.0-1.5 \mathrm{~J} \times 15-20 \mathrm{~Hz}$

- $0.2-0.4 \mathrm{~J} \times 30-50 \mathrm{~Hz}$

- $0.5 \times 20-50 \mathrm{~Hz}$

- no standard setting; it varies with the situation

- other

Question 26: Do you use Dusting settings at all (i.e., Low Pulse Energy, High frequency 0.2-0.5 J $\times 30-50 \mathrm{~Hz}$ )? Question 27: At the end of a routine flexible ureterorenoscopy to treat renal calculi

- I place a ureteral stent to be removed in the office at a later date

- I place an open-ended ureteral catheter, to be removed in 24 to 48 hours

- I don't place a stent or ureteral catheter

- Whether or not I stent depends on intraoperative factors (time of surgery, residual fragments, ureteral injury, etc.)

- I place a stent to be removed by patient at home (stent on string)

Question 28: Do you ever use stent on string placement after flexible ureterorenoscopy to treat renal stones?

- Never

- Occasionally

- Routinely 
Question 29: How many days is the maximum time you will instruct your patient to keep the stent (on a string)?

- 1 day

- 2 days

- 3 days

- 4 days

- 5 days

- $>7$ days

- It depends on the situation

Question 30: Do you or your center/practice maintain a ureteral stent registry to keep track and recall stents in patients? Question 31: What method is used to keep track of stents?

- Paper-based system: managed by physician

- Paper-based system: managed by administrative assistant(s)

- Electronic stent registry integrated with electronic patient record

- Electronic stent registry that is not integrated with electronic patient record

- Other

Question 32: Have you ever failed to remove a ureteral stent in timely manner with consequences of patient morbidity? Question 33: Have you ever managed a patient who had a forgotten ureteral stent?

Question 34: Which imaging modality do you use to determine stone free after flexible ureterorenoscopy?

- Kidney, ureter, and bladder radiograph (KUB) X-ray (XR) if stone radiopaque

- Ultrasound scan if stone is radiolucent

- KUB XR if radiopaque and ultrasound scan

- Ultrasound scan only regardless of stone lucency

- Non contrast CT of abdomen/pelvis

- Low-dose noncontrast CT of abdomen/pelvis

Question 35: At what time point do you assess stone-free rate after flexible ureterorenoscopy treatment for renal stones?

- 2 weeks

- 1 month

- 6 weeks

- 2 months

- 3 months

- 6 months

Question 36: What are the important stone size criteria for you when determining if a patient is stone-free?

- Patient must have zero fragments to be stone free

- $<1 \mathrm{~mm}$ fragment is $\mathrm{OK}$

- $<2 \mathrm{~mm}$ fragment is OK

- $<3 \mathrm{~mm}$ fragment is $\mathrm{OK}$

- $<4 \mathrm{~mm}$ fragment is OK

- $<5 \mathrm{~mm}$ fragment is $\mathrm{OK}$ 


\section{This article has been cited by:}

1. Natalia Hernandez Bustos, Alan Yaghoubian, Sarah Mozafarpour, Brian Eisner. History of the Development of Guidewires, Access Sheaths, Baskets, and Ureteral Stents 79-85. [Crossref]

2. Wesley Baas, Matthew Davis, Bradley F. Schwartz. Simulation in Surgery 439-488. [Crossref]

3. Takaaki Inoue, Shinsuke Okada, Shuzo Hamamoto, Takashi Yoshida, Tadashi Matsuda. 2017. Current trends and pitfalls in endoscopic treatment of urolithiasis. International Journal of Urology 35. . [Crossref]

4. Philippe F. Müller, Daniel Schlager, Simon Hein, Christian Bach, Arkadiusz Miernik, Dominik S. Schoeb. 2017. Robotic stone surgery - Current state and future prospects: A systematic review. Arab Journal of Urology . [Crossref]

5. Ali H. Aldoukhi, William W. Roberts, Timothy L. Hall, Khurshid R. Ghani. 2017. Holmium Laser Lithotripsy in the New Stone Age: Dust or Bust?. Frontiers in Surgery 4. . [Crossref]

6. Chan Luke H., Good Daniel W., Laing Karina, Phipps Simon, Thomas Ben G., Keanie Julian Y., Tolley David A., Cutress Mark L.. 2017. Primary SWL Is an Efficient and Cost-Effective Treatment for Lower Pole Renal Stones Between 10 and $20 \mathrm{~mm}$ in Size: A Large Single Center Study. Journal of Endourology 31:5, 510-516. [Abstract] [Full Text HTML] [Full Text PDF] [Full Text PDF with Links]

7. Francesco Sanguedolce, Giorgio Bozzini, Ben Chew, Panagiotis Kallidonis, Jean de la Rosette. 2017. The Evolving Role of Retrograde Intrarenal Surgery in the Treatment of Urolithiasis. European Urology Focus 3:1, 46-55. [Crossref]

8. Hai Wang, Libo Man, Guizhong Li, Guanglin Huang, Ning Liu, Jianwei Wang. 2017. Meta-Analysis of Stenting versus NonStenting for the Treatment of Ureteral Stones. PLOS ONE 12:1, e0167670. [Crossref]

9. Freton Lucas, Peyronnet Benoit, Arnaud Alexis, Tondut Lauranne, Hascoet Juliette, Pradère Benjamin, Verhoest Grégory, Habonimana Édouard, Azzis Olivier, Fremond Benjamin, Bensalah Karim. 2017. Extracorporeal Shockwave Lithotripsy Versus Flexible Ureteroscopy for the Management of Upper Tract Urinary Stones in Children. Journal of Endourology 31:1, 1-6. [Abstract] [Full Text HTML] [Full Text PDF] [Full Text PDF with Links]

10. Dauw Casey A., Borofsky Michael S., York Nadya, Lingeman James E.. 2016. Percutaneous Nephrolithotomy in the Superobese: A Comparison of Outcomes Based on Body Mass Index. Journal of Endourology 30:9, 987-991. [Abstract] [Full Text HTML] [Full Text PDF] [Full Text PDF with Links]

11. David Álvarez Villaraga, Juan David Iregui Parra, German Patiño Sandoval, Julián Chavarriaga Soto, Daniel Díaz Cardona. 2016. Ureterorrenoscopia flexible: estado del arte y guía práctica de consejos y trucos. Urología Colombiana 25:3, 239-249. [Crossref]

12. David Álvarez Villaraga, Juan David Iregui Parra, German Patiño Sandoval, Julián Chavarriaga Soto, Daniel Díaz Cardona. 2016. Flexible ureterorenoscopy: State of the art and practical guide of tips and tricks. Urología Colombiana 25:3, 250-260. [Crossref]

13. B.O. Manzo, M. Bertacchi, E. Lozada, A. Rasguido, E. Aleman, M. Cabrera, A. Rodríguez, G. Manzo, H. Sánchez, J. Blasco. 2016. Práctica actual de la ureteronefroscopia flexible con láser en América Latina para el tratamiento de la litiasis renal. Actas Urológicas Españolas 40:4, 229-236. [Crossref]

14. B.O. Manzo, M. Bertacchi, E. Lozada, A. Rasguido, E. Aleman, M. Cabrera, A. Rodríguez, G. Manzo, H. Sánchez, J. Blasco. 2016. Current practice in Latin America of flexible ureterorenoscopy with laser for treating kidney stones. Actas Urológicas Españolas (English Edition) 40:4, 229-236. [Crossref]

15. Deok Hyun Han, Seung Hyun Jeon. 2016. Stone-breaking and retrieval strategy during retrograde intrarenal surgery. Investigative and Clinical Urology 57:4, 229. [Crossref]

16. Jiaqiao Zhang, Chuou Xu, Deng He, Yuchao Lu, Henglong Hu, Baolong Qin, Yufeng Wang, Qing Wang, Cong Li, Shaogang Wang, Jihong Liu. 2016. Flexible ureteroscopy for renal stone without preoperative ureteral stenting shows good prognosis. PeerJ 4, e2728. [Crossref] 